OPEN ACCESS

Edited by:

Joanna Julia Domagala-Kulawik, Medical University of Warsaw, Poland

Reviewed by:

Frank Rassouli,

Kantonsspital St. Gallen, Switzerland

Pai-Chien Chou,

Taipei Medical University

Hospital, Taiwan

*Correspondence:

Vianey Rodriguez-Lara vianeyr@facmed.unam.mx

Specialty section:

This article was submitted to

Pulmonary Medicine,

a section of the journal

Frontiers in Medicine

Received: 28 August 2020 Accepted: 30 March 2021

Published: 17 May 2021

Citation:

Rodriguez-Lara V and Avila-Costa MR (2021) An Overview of Lung Cancer in Women and the Impact of Estrogen in

Lung Carcinogenesis and Lung

Cancer Treatment.

Front. Med. 8:600121.

doi: 10.3389/fmed.2021.600121

\section{An Overview of Lung Cancer in Women and the Impact of Estrogen in Lung Carcinogenesis and Lung Cancer Treatment}

\author{
Vianey Rodriguez-Lara ${ }^{1 *}$ and Maria Rosa Avila-Costa ${ }^{2}$ \\ ${ }^{1}$ Department of Cell and Tissue Biology, Faculty of Medicine, Universidad Nacional Autonoma de Mexico, Mexico City, \\ Mexico, ${ }^{2}$ Neuromorphology Laboratory, Facultad de Estudios Superiores Iztacala, Universidad Nacional Autonoma de \\ Mexico, Mexico City, Mexico
}

Lung cancer incidence and mortality have significantly increased in women worldwide. Lung adenocarcinoma is the most common form of lung cancer globally. This type of lung cancer shows differences by sex, including the mutational burden, behavior, clinical characteristics, and response to treatment. The effect of sex on lung cancer patients' survival is still controversial; however, lung adenocarcinoma is considered a different disease in women and men. Moreover, lung adenocarcinoma is strongly influenced by estrogen and is also different depending on the hormonal status of the patient. Young pre-menopausal women have been explored as an independent group. They presented in more advanced stages at diagnosis, exhibited more aggressive tumors, and showed poor survival compared to men and post-menopausal women, supporting the role of sex hormones in this pathology. Several reports indicate the estrogen's role in lung carcinogenesis and tumor progression. Thus, there are currently some clinical trials testing the efficacy of antihormonal therapy in lung cancer treatment. This mini review shows the updated data about lung cancer in women, its characteristics, the etiological factors that influence carcinogenesis, and the critical role of estrogen in lung cancer and treatment.

Keywords: lung cancer, women, estrogens, antiestrogen medication, adenocarcimoma

\section{INTRODUCTION}

Lung cancer in women (LCW) is a severe health problem globally. Smoking habits remain the main factor for its development; however, a high percentage of women with lung cancer (LC) are non-smokers. Therefore, the studies should focus on identifying the risk factors for LCW besides tobacco smoking. Recently, it has been reported that sex and sex hormones may influence LC behavior, survival, and treatment response.

\section{LCW Epidemiology}

LCW has significantly increased worldwide in the last years, while in men gradually has decreased, in women has exceeded the incidence and mortality reported for breast cancer, being the leading cause of cancer death in developed countries such as the United States and some from Europe (1-5). Nowadays, LCW has reached third place in incidence and the second place in mortality worldwide with an estimated of 725,352 cases and 576,060 deaths in $2018(6,7)$. 
By 2030, LCW is expected to increase $43 \%$ in 52 countries with a median of LC age-standardized mortality rates (ASMRs) rising from 11.2 to 16, which will exceed the ASMRs observed for breast cancer (8). Additionally, the current smoking prevalence in adolescent girls from low and middle-income countries of Africa, South America, and the Middle East is higher than that observed in many high-income countries (9), which will increase LCW incidence and mortality in the following years if smoking is not reduced.

LCW increase, mainly in developed countries, could be explained partially by the high tobacco intake (5-9). However, LC has also increased in non-smokers and young women worldwide. Moreover, only $50 \%$ of LCW is associated with tobacco smoke. Recently, Jemal and coworkers reported that the increased LC incidence in young women in the USA is not fully explained by smoking patterns (10). Other factors, in addition to tobacco smoking, are essential to developing LCW.

\section{Characteristics of LCW}

According to the histological features, two types of LC have been described: small-cell lung cancer and non-small cell lung cancer (NSCLC). Currently, the most common type of LC worldwide is the NSCLC, being $85 \%$ of all LC diagnosed. There are three NSCLC subtypes: squamous cell carcinoma, lung adenocarcinoma, and large cell carcinoma. Approximately 40 to $60 \%$ of LCW correspond to adenocarcinoma, while squamous cell carcinoma is about 10 to $30 \%$ of all LC diagnosed (11-13). Lung adenocarcinoma is a heterogeneous type of cancer and exhibits a lesser association with smoking habits compared to other LC subtypes. It is estimated that up to $50 \%$ of women with lung adenocarcinoma are non-smokers, compared to $10-15 \%$ of non-smoking men who develop this type of cancer (14).

Clinical characteristics are different between women and men; the diagnosis age in women is lower, women more often have a non-smoking habit, present less advanced stages at diagnosis, and the outcome and survival are significantly better at all stages (11). Hormonal status is rarely considered in studies; however, when pre-menopausal women have been studied independently, they were more commonly diagnosed in advanced stages, exhibited less differentiated tumors, and showed a higher number of metastases and poor prognosis compared to post-menopausal women and men (15-18). It was recently reported that premenopausal women exhibit lower overall survival than men and post-menopausal women, supporting the role of sex hormones in LC progression (19).

It is also noteworthy that women with NSCLC respond differently to treatments, being more responsive to chemotherapy (mainly platinum-based treatment), those with adenocarcinoma histology type (13), and for the therapy-based on tyrosine kinase inhibitors (TKIs), but less sensitive to immunotherapy (20-22).

Some LC mutations are more frequent in women, and some genes are differentially expressed by sex. The cytochrome CYP1A1 is overexpressed in women (23), partially explaining tobacco carcinogens' highest susceptibility, since CYP1A1 bioactivates these compounds. Women have a reduced DNA repair capacity (23) and increased gastrin-releasing peptide receptor (GRPR) that stimulate cancer cell proliferation.
Tobacco-related p53 mutations are also more frequent in women $(24,25)$. All these data suggest that women are more susceptible to tobacco carcinogens than men.

Moreover, women are more likely to be ERCC1-negative, which could explain the chemotherapy treatment benefit compared to men. The Kristen rat sarcoma virus (KRAS) and epidermal growth factor receptor (EGFR) are often overexpressed in women's lung adenocarcinoma (25). Mutations in EGFR (exon 18-21) are more frequent in women and are associated with estrogen receptor expression (25-28).

\section{LCW Etiological Factors}

Tobacco smoking remains an essential factor associated with LCW, being more susceptible and having more risk of developing LC than men even in similar smoking exposure (29). The increased incidence of LCW in developed countries has been associated with the changes in smoking habit; however, LCW has risen in young women (30) and even in non-smokers (31), supporting the importance other factors have in lung carcinogenesis in women.

Secondhand smoke is a relevant risk factor in non-smoker women; $64 \%$ of deaths due to LC associated with secondhand smoke correspond to women. The passive smoker is exposed to two sources of carcinogens: the smoke generated by the cigarette combustion and the smoker's smoke exhales. The benzo-a-pyrene diol epoxide, a primary carcinogen of tobacco, is found in both sources (32).

Wood smoke exposure (WSE) affects women mainly in developing countries, where wood is used for cooking and keeping the home warm. For example, it is estimated that $34.4 \%$ of non-smoking patients with LC in Mexico were chronically exposed to wood smoke. WSE is associated with adenocarcinoma subtype and higher EGFR mutation (33). WSE produces an increase in MMP-2 and MMP-9, DNA breaks strand, and adducts (34). Deregulation in pathways such as PI3K/AKT, MEK/ERK, and genes involved in DNA repair, cell cycle, apoptosis, and vesicle transport have also been observed in WSE patients with LC (35).

Among non-smokers women, who develop LC in China and India, cooking oil fumes is an important risk factor for developing LC (36). When cooking, oil is brought to high temperatures and generates fumes that contain lung carcinogens, such as polycyclic aromatic hydrocarbons, which produce DNAoxidative damage and lipid peroxidation (37).

Ambient air pollution, mainly particulate matter (PM2.5), is also associated with a high risk for LC (38), being that the hydrocarbons and heavy metals in the PM compounds carry carcinogenic potential. PM exposure produces inflammation associated with LC (39). Some reports have found that women exhibit a higher risk to air pollution than men (40-42), probably due to their higher susceptibility to carcinogens, reduced DNA repair capacity, and polymorphisms of xenobiotic-metabolizing genes. Ambient air pollution remains a significant risk factor for developing LC in non-smoking women who live in cities with high air pollution levels (43).

Previous reports indicated that the human papillomavirus (HPV) infection could be associated with LCW, since DNA from 
HPV16, 18, 30, 31, 33, and 39 were detected in women LC tissues (44-46); however, recent studies rule out this association, since there is no evidence of DNA from HPV in lung tumors, and no differences were found between the presence of HVP in lung tumors and controls (47-49).

Although secondhand smoke, wood combustion, cooking oil fumes, and air pollution are other risk factors to develop LC, particularly in non-smoking women, this does not fully explain the higher LC incidence because a considerable percentage of women were not exposed to these factors. Therefore, it is necessary to identify other etiological factors associated with LCW since up to $50 \%$ of cases exhibit non-smoking association.

\section{Estrogen Role in Lung Carcinogenesis}

Estrogens (E2), through their receptors (ER), regulate several biologic events in addition to their reproductive function. Nuclear estrogen receptor alpha $(\mathrm{ER} \alpha)$ and beta $(\mathrm{ER} \beta)$ are expressed in lung tissue from women and men, playing a role in lung development and physiology (50). The estrogen pathway has also been related to lung carcinogenesis (15).

\section{Estrogen Receptors and Aromatase Expression in NSCLC}

ER expression has been detected in tumors from patients and NSCLC cell lines (51) and is overexpressed, mainly in lung adenocarcinoma. The ER $\beta$ is the most abundant form of ER in LC; it is overexpressed in $60-80 \%$ of tumors from women and men (52), and it is related to mutations in $\sim 500$ genes (53).

$\operatorname{ER} \beta$ expression is associated with hormonal status. The highest expression was found in tumors from pre-menopausal women; lower expression was observed in post-menopausal women. The minimum expression was observed in men (16), suggesting the critical role of circulating estrogen in ER expression.

The G protein-coupled estrogen receptor (GPER) has also been identified in the cytoplasm of NSCLC tumors from women and men, showing higher expression and activity than normal bronchial epithelium (54). GPER expression was associated with LC IIIA and IV stages, lymphoid node metastases, and poorly differentiated tumors. In vitro, estrogen increased cell proliferation, migration, and invasion through GPER (55).

Aromatase enzyme (ARO) has been detected in NSCLC cell lines and $\sim 86 \%$ of tumors. Through ARO, the tumor produces estrogen and activates the estrogen pathway; consequently, it is stimulated by circulating and locally produced estrogen (56). Metastases sites exhibit higher ARO expression than the primary tumor; thus, local estrogen production might also induce the metastases in LC (57).

\section{Exogenous Estrogen Exposure and LC Risk}

Exogenous estrogen intake and LC risk have also been investigated; however, the results are still controversial. Several studies have shown that hormonal replacement therapy (HRT) is associated with decreased risk of LC and may have a protective effect on the development of NSCLC in women $(58,59)$. In contrast, some studies report that HRT increases LC incidence $(60,61)$. A prospective study involved 36,588 women who use combined HRT estrogen-based plus progestin showed $50 \%$ of increased risk after ten or more years of treatment (60). Moreover, the women's health initiative studies showed that combined HRT was unrelated to LC incidence. Still, a relation to increased mortality from LC, less differentiated tumors, and distant metastases were observed (62). Poor survival in women who use HRT before cancer diagnosis was found compared to women who never use it (39 vs. 79 months) (63). LC risk decreased after HRT cessation (61).

Regarding contraceptive intake, studies found no association with LC increased incidence (64); however, Iversen and coworkers (65) reported an increased risk among ever users who have smoked. The risk of contraceptive intake once LC is developed has not been investigated.

Another exposure form to exogenous estrogen is through endocrine disruptors such as Bisphenol-A (BPA), promoting the migration and invasion of LC cells (66). It was recently reported in the Chinese population that BPA levels were significantly higher in NSCLC patients than in healthy controls; therefore, BPA exposure may be an important risk factor (67).

Estrogen intake does not appear to increase the LC risk; however, once the disease is established, it may increase mortality, probably due to the carcinogenic mechanisms activated by the estrogen pathway.

\section{Estrogen Pathway in Lung Carcinogenesis}

Estrogen metabolites generate reactive oxygen species (ROS) that cause DNA oxidative damage and form adducts by associating directly to DNA, causing mutations (52). Moreover, through the genomic pathway, the E2/ER complex promotes NSCLC cell proliferation and cell cycle progression by inducing the estrogen expression-dependent genes, $\mathrm{c}-\mathrm{myc}$, cyclin $\mathrm{D}$, and Id proteins genes $(68,69)$. By the non-genomic pathway, E2 activates several pathways that sustain cell proliferation and stimulate tumor growth, such as AMPc, PI3K, MAPK, AKT, and ERK $(69,70)$.

The EGFR pathway is one of the most important signaling pathways in NSCLC since $89 \%$ of patients exhibit EGFR overexpression or mutation (71). In NSCLC, E2 activates the EGFR pathway even in the absence of its ligand, promoting cell proliferation, survival, angiogenesis, cell migration, and metastases (72). ER $\beta$ expression has also been associated with EGFR mutations (73).

Additionally, estrogen induces angiogenesis through vascular endothelial growth factor (VEGF-A), the ligand of VEGFR2 expressed in endothelial cells. VEGFR activation produces endothelial cell proliferation to form new vessels that support tumor growth (68).

In vitro, E2 stimulated CXCR4 expression and CXCL12/CXCR4 pathway activation in a time and dosedependent manner, resulting in cell migration (74). This pathway also supports cell proliferation, survival, apoptosis resistance, and angiogenesis and stimulates migration and metastases to the brain, bone, liver, and lymph nodes, the main metastases sites of NSCLC. CXCR4 activation is also related to chemoresistance, maintenance of stem cell characteristics in tumor cells, and immunoresistance by recruiting regulatory $\mathrm{T}$ cells (Tregs) to the tumor microenvironment $(75,76)$.

Estrogen modulates the immune response by modifying the tumor microenvironment, stimulating pro-inflammatory 


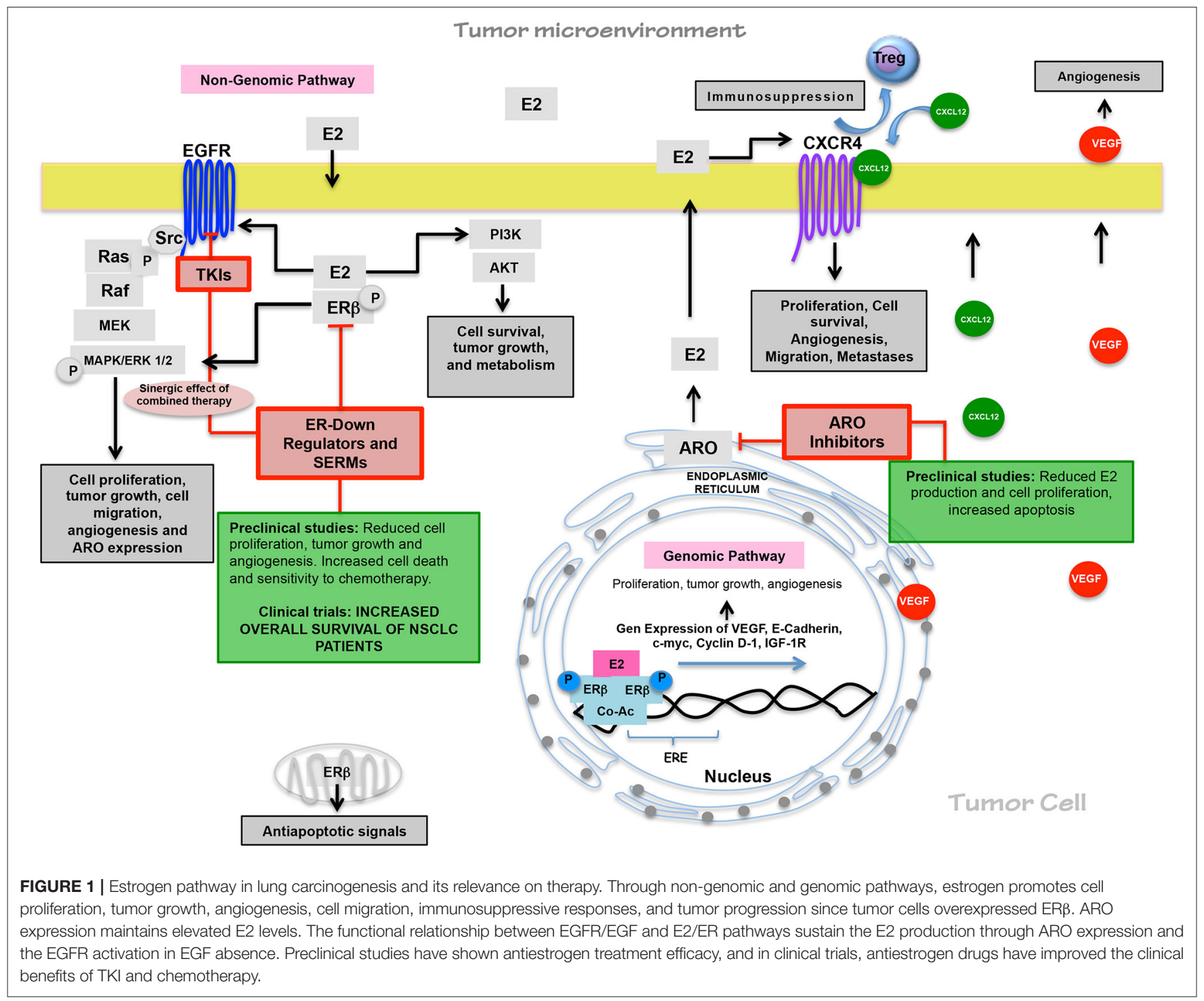

cytokines, recruiting Tregs, and promoting cell migration (77). Estrogen induces VEGF secretion by tumor-associated macrophages (TAMs), which support an immunosuppressive tumor microenvironment. $\mathrm{ER} \alpha$ expression in lung adenocarcinoma is also associated with Treg recruitment and immunosuppressive response (78).

Nowadays, we know that the estrogen pathway has an essential role in NSCLC, mainly in lung adenocarcinoma, promoting several cancer hallmarks, including cell proliferation, apoptosis resistance, angiogenesis, tumor cell migration and metastases, and probably immune evasion. However, further studies are necessary to fully understand this hormone's relationship with LC progression (Figure 1).

\section{Estrogen Pathway Relevance as a Target in LC Treatment}

The antiestrogen drug's efficacy has been tested in in-vitro and in-vivo assays in NSCLC. Aromatase inhibitors, such as letrozole, significantly decrease cell proliferation, while exemestane reduces tumor growth, increases cell apoptosis, and inhibits cell migration and invasion in vitro (79). The treatment with the estrogen receptor inhibitor, fulvestrant, decreases the tumor growth, the ER $\beta$ expression, and the mesenchymal features induced by E2 also increases the chemotherapy sensitivity and T lymphocytes activity (80).

The use of antiestrogen drugs was retrospectively investigated. A higher survival was reported in women who used this therapy previously to be diagnosed with NSCLC than women who never used antiestrogenic treatment (1.89 years vs. 0.93 years, respectively) (81). Also, in clinical trial phases I and II, tamoxifen increased the cisplatin toxicity, and the response to combined therapy was higher than chemotherapy (82). Combined treatment with docetaxel/fulvestrant produced a higher response and overall survival in advanced NSCLC patients than individual chemotherapy (83).

Additionally, the effect of combined antiestrogen and TKI therapy has been investigated in NSCLC due to the functional 
relationship between estrogen and EGFR pathways. In vitro, antiestrogen treatment prevents cell proliferation, stimulates apoptosis, reduces tumor growth, and increases the gefitinib sensitivity $(84,85)$. A phase I clinical trial tested gefitinib plus fulvestrant efficacy. The results showed improved overall survival in NSCLC patients with a mean of 65.5 weeks in those with higher ER $\beta$ tumor expression (86). Also, combined therapy (erlotinib/fulvestrant) has been well-tolerated and demonstrates more clinical benefit than TKI monotherapy $(87,88)$.

Currently, the effectiveness of antiestrogenic therapy on LC is still being investigated. Approximately ten clinical trials study the effects of antiestrogen therapy alone or combined, mainly with TKI, showing clinical benefits in NSCLC patients. These results will be relevant to propose new treatment schemes in LCW patients (Figure 1).

\section{DISCUSSION}

LCW has significantly increased, even in young and non-smoking women worldwide. Thus, it is necessary to explore the risk factors that explain this occurrence in the female population to strengthen prevention strategies.

The estrogen pathway has shown an important role in lung carcinogenesis, tumor progression, response to treatment, and survival. The exogenous estrogen could be an important risk factor in women with LC and those with a high risk of developing this disease due to a high percentage of NSCLC express ER/ARO.

Although some estrogen pathways in lung carcinogenesis have been investigated, further studies are necessary to fully understand its role in this disease and its relationship with

\section{REFERENCES}

1. Malvezzi M, Carioli G, Bertuccio P, Boffetta P, Levi F, La Vecchia C, et al. European cancer mortality predictions for the year 2017 with focus on lung cancer. Ann Oncol. (2017) 28:1117-23. doi: 10.1093/annonc/ $\mathrm{mdx} 033$

2. Egleston BL, Meireles SI, Flieder DB, Clapper ML. Population-based trends in lung cancer incidence in women. Semin Oncol. (2009) 36:50615. doi: 10.1053/j.seminoncol.2009.09.003

3. Henley SJ, Gallaway S, Singh SD, O’Neil ME, Buchanan Lunsford N, Momin B, et al. Lung cancer among women in the United States. J Womens Heal. (2018) 27:1307-6. doi: 10.1089/jwh.2018.7397

4. de Groot PM, Wu CC, Carter BW, Munden RF. The epidemiology of lung cancer. Transl Lung Cancer Res. (2018) 7:220-33. doi: 10.21037/tlcr.2018.05.06

5. Barta JA, Powell CA, Wisnivesky JP. Global epidemiology of lung cancer. Ann Glob Heal. (2019) 85:8. doi: 10.5334/aogh.2419

6. Globocan. Global Cancer Burden in 2018. (2018). Available online at: http:// gco.iarc.fr

7. Siegel RL, Miller KD, Jemal A. Cancer statistics 2020. CA Cancer J Clin. (2020) 70:7-30. doi: 10.3322/caac. 21590

8. Martin-Sanchez JC, Lunet N, Gonzalez-Marron A, Lidon-Moyano C, Matilla-Santander N, Cleries R, et al. Projections in breast and lung cancer mortality among women: a bayesian analysis of 52 countries worldwide. Cancer Res. (2018) 78:4436-2. doi: 10.1158/0008-5472.CAN18-0187

9. Torre LA, Islami F, Siegel RL, Ward EM, Jemal A. Global cancer in women: burden and trends. Cancer Epidemiol Biomarkers Prev. (2017) 26:44457. doi: 10.1158/1055-9965.EPI-16-0858 different critical pathways blocked in targeted therapy to enhance its clinical benefit and decrease the resistance.

Since NSCLC is a different disease in women than in men, and hormonal status influences the behavior of LC, future studies must include the highest number of women as possible; also, it is essential to separate women by hormonal status since very few studies have evaluated this variable and could provide vital information to improve the treatment in young pre-menopausal women, whose frequently are diluted in most studies and shows the worst prognosis.

Finally, it is essential to propose specific therapeutic schemes in LC treatment that consider the differences in LC behavior in women since women and men are treated similarly, independently of sex and hormonal status. Because of the relevance that the estrogen pathway has in LC, and with the high percentage of ER expression in LC patients (60-80\%), antiestrogen therapy would be an important option for LC treatment. ER detection in NSCLC could be considered in the future to propose better treatment options for women; however, more research is needed in this area.

\section{AUTHOR CONTRIBUTIONS}

All authors listed have made a substantial, direct and intellectual contribution to the work, and approved it for publication.

\section{ACKNOWLEDGMENTS}

The authors wish to thank the Research Division of the Medical School, UNAM, for the financial support.
10. Jemal A, Miller KD, Ma J, Siegel RL, Fedewa SA, Islami F, et al. Higher lung cancer incidence in young women than young men in the United States. $N$ Engl J Med. (2018) 378:1999-2009. doi: 10.1056/NEJMoa1715907

11. Radkiewicz C, Dickman PW, Johansson ALV, Wagenius G, Edgren G, Lambe M. Sex and survival in non-small cell lung cancer: a nationwide cohort study. PLoS ONE. (2019) 14:e0219206. doi: 10.1371/journal.pone.0219206

12. North CM, Christiani DC. Women and lung cancer: what is new? Semin Thorac Cardiovasc Surg. (2013) 25:87-94. doi: 10.1053/j.semtcvs.2013.05.002

13. Barrera-Rodriguez R, Morales-Fuentes J. Lung cancer in women. Lung Cancer. (2012) 3:79-89. doi: 10.2147/LCTT.S37319

14. Nagy-Mignotte H, Guillem P, Vesin A, Toffart AC, Colonna M, Bonneterre V, et al. Primary lung adenocarcinoma: characteristics by smoking habit and sex. Eur Respir J. (2011) 38:1412-9. doi: 10.1183/09031936.00191710

15. Rodriguez-Lara V, Hernandez-Martinez JM, Arrieta O. Influence of estrogen in non-small cell lung cancer and its clinical implications. J Thorac Dis. (2018) 10:482-97. doi: 10.21037/jtd.2017.12.61

16. Rodriguez-Lara V, Pena-Mirabal E, Baez-Saldana R, Esparza-Silva AL, Garcia-Zepeda E, Cerbon Cervantes MA, et al. Estrogen receptor beta and CXCR4/CXCL12 expression: differences by sex and hormonal status in lung adenocarcinoma. Arch Med Res. (2014) 45:158-69. doi: 10.1016/j.arcmed.2014.01.001

17. Stabile LP, Dacic S, Land SR, Lenzner DE, Dhir R, Acquafondata M, et al. Combined analysis of estrogen receptor beta-1 and progesterone receptor expression identifies lung cancer patients with poor outcome. Clin Cancer Res. (2011) 17:154-64. doi: 10.1158/1078-0432.CCR-10-0992

18. Albain KS, Unger JM, Gotay CC, Davies M, Edelman M, Herbst RS, et al. Toxicity and survival by sex in patients with advance non-small cell lung carcinoma on modern Southwest Oncology Group (SWOG) trials. J Clin Oncol. (2007) 25:7549. doi: 10.1200/jco.2007.25.18_suppl.7549 
19. Rodriguez-Lara V, Ramirez-Tirado LA, Barron F, Zatarain-Barron ZL, FloresEstrada D, Arrieta O. Characteristics of non-small cell lung cancer: differences by sex and hormonal status in a Mexican population. Salud Publica Mex. (2019) 61:265-75. doi: 10.21149/10094

20. Pinto JA, Vallejos CS, Raez LE, Mas LA, Ruiz R, Torres-Roman JS, et al. Gender and outcomes in non-small cell lung cancer: an old prognostic variable comes back for targeted therapy and immunotherapy? ESMO Open. (2018) 3:e000344. doi: 10.1136/esmoopen-2018-000344

21. Conforti F, Pala L, Bagnardi V, De Pas T, Martinetti M, Viale $\mathrm{G}$, et al. Cancer immunotherapy efficacy and patients' sex: a systematic review and meta-analysis. Lancet Oncol. (2018) 19, 737-46. doi: 10.1016/S1470-2045(18)30261-4

22. Wang S, Cowley LA, Liu XS. Sex differences in cancer immunotherapy efficacy, biomarkers, and therapeutic strategy. Molecules. (2019) 24:3214. doi: 10.3390/molecules24183214

23. Kirsch-Volders M, Bonassi S, Herceg Z, Hirvonen A, Moller L, Phillips $\mathrm{DH}$. Gender-related differences in response to mutagens and carcinogens. Mutagenesis. (2010) 25:213-21. doi: 10.1093/mutage/geq008

24. Kligerman S, White C. Epidemiology of lung cancer in women: risk factors, survival, and screening. Am J Roentgenol. (2011) 196:28795. doi: 10.2214/AJR.10.5412

25. Planchard D, Loriot Y, Goubar A, Commo F, Soria JC. Differential expression of biomarkers in men and women. Semin Oncol. (2009) 36:55365. doi: 10.1053/j.seminoncol.2009.09.004

26. Li JY, Liu Y, Deng AP. Analysis of the EGFR gene mutation in patients with nonsmall cell lung cancer in a Chinese population. Trop J Pharm Res. (2016) 15:1637-41.doi: 10.4314/tjpr.v15i8.6

27. Rosell R, Moran T, Queralt C, Porta R, Cardenal F, Camps C, et al. Screening for epidermal growth factor receptor mutations in lung cancer. $N$ Engl J Med. (2009) 361:958-67. doi: 10.1056/NEJMoa0904554

28. Ding $\mathrm{X}, \mathrm{Li} \mathrm{L}$, Tang C, Meng C, Xu W, Wei X, et al. Cytoplasmic expression of estrogen receptor $\beta$ may predict poor outcome of EGFR-TKI therapy in metastatic lung adenocarcinoma. Oncol Lett. (2018) 16:238290. doi: 10.3892/ol.2018.8936

29. Engeland A. Trends in the incidence of smoking-associated cancers in Norway, 1954-1993. Int J Cancer. (1996) 68:3946.doi: 10.1002/(SICI)1097-0215(19960927)68:1<39::AID-IJC>3.0.CO;2-Y; 39::AID-IJC8\&gt;3.0.CO;2-Y

30. Fidler-Benaoudia MM, Torre LA, Bray F, Ferlay J, Jemal A. Lung cancer incidence in young women vs. young men: a systematic analysis in 40 countries. Int J Cancer. (2020) 147:811-9. doi: 10.1002/ijc.32809

31. Liang D, Wang J, Li D, Shi J, Jing J, Shan B, et al. Lung cancer in neversmokers: a multicenter case-control study in North China. Front Oncol. (2019) 9:1354. doi: 10.3389/fonc.2019.01354

32. Dela Cruz CS, Tanoue LT, Matthay RA. Lung cancer: epidemiology, etiology, and prevention. Clin Chest Med. (2011) 32:60544. doi: 10.1016/j.ccm.2011.09.001

33. Arrieta O, Campos-Parra AD, Zuloaga C, Aviles A, Sanchez-Reyes $\mathrm{R}$, Manriquez $\mathrm{ME}$, et al. Clinical and pathological characteristics, outcome and mutational profiles regarding non-small-cell lung cancer related to wood-smoke exposure. J Thorac Oncol. (2012) 7:1228-34. doi: 10.1097/JTO.0b013e3182582a93

34. Delgado J, Martinez LM, Sanchez TT, Ramirez A, Iturria C, Gonzalez-Avila G. Lung cancer pathogenesis associated with wood smoke exposure. Chest. (2005) 128:124-31. doi: 10.1378/chest.128.1.124

35. Ortega-Gomez A, Rangel-Escareno C, Molina-Romero C, MacedoPerez EO, Aviles-Salas A, Lara-Garcia A, et al. Gene-expression profiles in lung adenocarcinomas related to chronic wood smoke or tobacco exposure. Respir Res. (2016) 17:42. doi: 10.1186/s12931-0160346-3

36. Chen TY, Fang YH, Chen HL, Chang CH, Huang H, Chen YS, et al. Impact of cooking oil fume exposure and fume extractor use on lung cancer risk in non-smoking Han Chinese women. Sci Rep. (2020) 10:6774. doi: 10.1038/s41598-020-63656-7

37. Xue Y, Jiang Y, Jin S, Li Y. Association between cooking oil fume exposure and lung cancer among Chinese nonsmoking women: a meta-analysis. Onco Targets Ther. (2016) 9:2987-92. doi: 10.2147/OTT.S100949
38. Gharibvand L, Lawrence Beeson W, Shavlik D, Knutsen R, Ghamsary M, Soret $\mathrm{S}$, et al. The association between ambient fine particulate matter and incident adenocarcinoma subtype of lung cancer. Env Heal. (2017) 16:71. doi: 10.1186/s12940-017-0268-7

39. Li R, Zhou R, Zhang J. Function of PM2.5 in the pathogenesis of lung cancer and chronic airway inflammatory diseases. Oncol Lett. (2018) 15:750614. doi: 10.3892/ol.2018.8355

40. Liu G, Sun B, Yu L, Chen J, Han B, Li Y, et al. The gender-based differences in vulnerability to ambient air pollution and cerebrovascular disease mortality: evidences based on 26781 deaths. Glob Hear. (2020) 15:46. doi: 10.5334/ gh.849

41. Kim H, Noh J, Noh Y, Oh SS, Koh SB, Kim C. Gender difference in the effects of outdoor air pollution on cognitive function among elderly in Korea. Front Public Heal. (2019) 7:375. doi: 10.3389/fpubh.2019.00375

42. Guo Y, Zeng H, Zheng R, Li S, Barnett AG, Zhang S, et al. The association between lung cancer incidence and ambient air pollution in China: a spatiotemporal analysis. Env Res. (2016) 144:60-5. doi: 10.1016/j.envres.2015.11.004

43. Chiu HF, Cheng MH, Tsai SS, Wu TN, Kuo HW, Yang CY. Outdoor air pollution and female lung cancer in Taiwan. Inhal Toxicol. (2006) 18:102531. doi: 10.1080/08958370600904561

44. de Freitas AC, Gurgel AP, de Lima EG, de Franca Sao Marcos B, do Amaral CM. Human papillomavirus and lung cancinogenesis: an overview. J Cancer Res Clin Oncol. (2016) 142:2415-27. doi: 10.1007/s00432-016-2197-1

45. Srinivasan M, Taioli E, Ragin CC. Human papillomavirus type 16 and 18 in primary lung cancers-a meta-analysis. Carcinogenesis. (2009) 30:17228. doi: $10.1093 /$ carcin/bgp177

46. Wang Y, Wang A, Jiang R, Pan H, Huang B, Lu Y, et al. Human papillomavirus type 16 and 18 infection is associated with lung cancer patients from the central part of China. Oncol Rep. (2008) 20:333-9. doi: 10.3892/or_00000011

47. Silva EM, Mariano VS, Pastrez PRA, Pinto MC, Nunes EM, Sichero L, et al. Human papillomavirus is not associated to non-small cell lung cancer: data from a prospective cross-sectional study. Infect Agent Cancer. (2019) 14:18. doi: 10.1186/s13027-019-0235-8

48. Argyri E, Tsimplaki E, Marketos C, Politis G, Panotopoulou E. Investigating the role of human papillomavirus in lung cancer. Papillomavirus Res. (2017) 3:7-10. doi: 10.1016/j.pvr.2016.12.002

49. He F, Xiong W, Yu F, Xiao R, Ye H, Li W, et al. Human papillomavirus infection maybe not associated with primary lung cancer in the Fujian population of China. Thorac Cancer. (2020) 11:561-9. doi: 10.1111/1759-7714.13282

50. Tam A, Morrish D, Wadsworth S, Dorscheid D, Man SF, Sin DD. The role of female hormones on lung function in chronic lung diseases. BMC Womens Heal. (2011) 11:24. doi: 10.1186/1472-6874-11-24

51. Mollerup S, Jorgensen K, Berge G, Haugen A. Expression of estrogen receptors alpha and beta in human lung tissue and cell lines. Lung Cancer. (2002) 37:153-9. doi: 10.1016/S0169-5002(02)00039-9

52. Hershberger PA, Stabile LP, Kanterewicz B, Rothstein ME, Gubish CT, Land $\mathrm{S}$, et al. Estrogen receptor beta (ERbeta) subtype-specific ligands increase transcription, p44/p42 mitogen activated protein kinase (MAPK) activation and growth in human non-small cell lung cancer cells. J Steroid Biochem Mol Biol. (2009) 116:102-9. doi: 10.1016/j.jsbmb.2009.05.004

53. Kerr 2nd A, Eliason JF, Wittliff JL. Steroid receptor and growth factor receptor expression in human nonsmall cell lung cancers using cells procured by laser-capture microdissection. Adv Exp Med Biol. (2008) 617:37784. doi: 10.1007/978-0-387-69080-3_36

54. Jala VR, Radde BN, Haribabu B, Klinge CM. Enhanced expression of Gprotein coupled estrogen receptor (GPER/GPR30) in lung cancer. $B M C$ Cancer. (2012) 12:624. doi: 10.1186/1471-2407-12-624

55. Liu C Fan S, Tang H, Jiang Z, Zhou B, Xiong J, Zhou S, et al. G proteincoupled estrogen receptor (GPER) mediates NSCLC progression induced by $17 \beta$-estradiol (E2) and selective agonist G1. J Med Oncol. (2015) 32:113. doi: 10.1007/s12032-015-0558-2

56. Skjefstad K, Grindstad T, Khanehkenari MR, Richardsen E, Donnem T, Kilvaer T, et al. Prognostic relevance of estrogen receptor alpha, beta and aromatase expression in non-small cell lung cancer. Steroids. (2016) 113:513. doi: 10.1016/j.steroids.2016.05.008 
57. Niikawa H, Suzuki T, Miki Y, Suzuki S, Nagasaki S, Akahira $\mathrm{J}$, et al. Intratumoral estrogens and estrogen receptors in human non-small cell lung carcinoma. Clin Cancer Res. (2008) 14:4417-26. doi: 10.1158/1078-0432.CCR-07-1950

58. Li W, Lin X, Wang R, Wang F, Xie S, Tse LA. Hormone therapy and lung cancer mortality in women: systematic review and meta-analysis. Steroids. (2017) 118:47-54. doi: 10.1016/j.steroids.2016.12.005

59. Titan AL, He H, Lui N, Liou D, Berry M, Shrager JB, et al. The influence of hormone replacement therapy on lung cancer incidence and mortality. J Thorac Cardiovasc Surg. (2020) 159:1546-56.e4. doi: 10.1016/j.jtcvs.2019.10.070

60. Slatore CG, Chien JW, Au DH, Satia JA, White E. Lung cancer and hormone replacement therapy: association in the vitamins and lifestyle study. J Clin Oncol. (2010) 28:1540-6. doi: 10.1200/JCO.2009.25.9739

61. Chlebowski RT, Wakelee H, Pettinger M, Rohan T, Liu J, Simon M, et al. Estrogen plus progestin and lung cancer: follow-up of the women's health initiative randomized trial. Clin Lung Cancer. (2016) 17:107.e1. doi: 10.1016/j.cllc.2015.09.004

62. Chlebowski RT, Schwartz AG, Wakelee H, Anderson GL, Stefanick ML, Manson JE, et al. Oestrogen plus progestin and lung cancer in postmenopausal women (Women's health initiative trial): a posthoc analysis of a randomised controlled trial. Lancet. (2009) 374:124351. doi: 10.1016/S0140-6736(09)61526-9

63. Ganti AK, Sahmoun AE, Panwalkar AW, Tendulkar KK, Potti A. Hormone replacement therapy is associated with decreased survival in women with lung cancer. J Clin Oncol. (2006) 24:59-63. doi: 10.1200/JCO.2005.02.9827

64. Wu W, Yin ZH, Guan P, Ren YW, Zhou BS. Association of oral contraceptives use and lung cancer risk among women: an updated meta-analysis based on cohort and case-control studies. Asian Pac J Cancer Prev. (2014) 15:120510. doi: 10.7314/APJCP.2014.15.3.1205

65. Iversen L, Sivasubramaniam S, Lee AJ, Fielding S, Hannaford PC. Lifetime cancer risk and combined oral contraceptives: the royal college of general practitioners' oral contraception study. Am J Obs Gynecol. (2017) 216:580 e1-0 e9. doi: 10.1016/j.ajog.2017.02.002

66. Zhang KS, Chen HQ, Chen YS, Qiu KF, Zheng XB, Li GC, et al. Bisphenol A stimulates human lung cancer cell migration via upregulation of matrix metalloproteinases by GPER/EGFR/ERK1/2 signal pathway. Biomed Pharmacother. (2014) 68:1037-43. doi: 10.1016/j.biopha.2014.09.003

67. Li J, Ji Z, Luo X, Li Y, Yuan P, Long J, et al. Urinary bisphenol A and its interaction with ESR1 genetic polymorphism associated with non-small cell lung cancer: findings from a case-control study in Chinese population. Chemosphere. (2020) 254:126835. doi: 10.1016/j.chemosphere.2020.126835

68. Marquez-Garban DC, Mah V, Alavi M, Maresh EL, Chen HW, Bagryanova L, et al. Progesterone and estrogen receptor expression and activity in human non-small cell lung cancer. Steroids. (2011) 76:910-20. doi: 10.1016/j.steroids.2011. 04.015

69. Hershberger PA, Vasquez AC, Kanterewicz B, Land S, Siegfried JM, Nichols M. Regulation of endogenous gene expression in human non-small cell lung cancer cells by estrogen receptor ligands. Cancer Res. (2005) 65:1598605. doi: 10.1158/0008-5472.CAN-04-2694

70. Marquez-Garban DC, Chen HW, Goodglick L, Fishbein MC, Pietras RJ. Targeting aromatase and estrogen signaling in human non-small cell lung cancer. Ann N Y Acad Sci. (2009) 1155:194-205. doi: 10.1111/j.1749-6632.2009.04116.x

71. Prabhakar CN. Epidermal growth factor receptor in non-small cell lung cancer. Transl Lung Cancer Res. (2015) 4:110-8. doi: 10.3978/j.issn.2218-6751.2015.01.01

72. Bethune G, Bethune D, Ridgway N, Xu Z. Epidermal growth factor receptor (EGFR) in lung cancer: an overview and update. J Thorac Dis. (2010) 2:48-51.

73. Deng F, Li M, Shan WL, Qian LT, Meng SP, Zhang XL, et al. Correlation between epidermal growth factor receptor mutations and the expression of estrogen receptor-beta in advanced non-small cell lung cancer. Oncol Lett. (2017) 13:2359-65. doi: 10.3892/ol.201 7.5711

74. Rodriguez-Lara V, Ignacio GS, Cerbon Cervantes MA. Estrogen induces CXCR4 overexpression and CXCR4/CXL12 pathway activation in lung adenocarcinoma cells in vitro. Endocr Res. (2017) 42:219-31. doi: 10.1080/07435800.2017.1292526

75. Xie S, Tu Z, Xiong J, Kang G, Zhao L, Hu W, et al. CXCR4 promotes cisplatinresistance of non-small cell lung cancer in a CYP1B1-dependent manner. Oncol Rep. (2017) 37:921-8. doi: 10.3892/or.2016.5289

76. Li Z, Wang Y, Shen Y, Qian C, Oupicky D, Sun M. Targeting pulmonary tumor microenvironment with CXCR4-inhibiting nanocomplex to enhance anti-PD-L1 immunotherapy. Sci Adv. (2020) 6:eaaz9240. doi: 10.1126/sciadv.aaz9240

77. Rothenberger NJ, Somasundaram A, Stabile LP. The role of the estrogen pathway in the tumor microenvironment. Int J Mol Sci. (2018) 19:611. doi: 10.3390/ijms19020611

78. Navarro FC, Herrnreiter C, Nowak L, Stephanie K, Watkins CH. Estrogen regulation of T-cell function and its impact on the tumor microenvironment. Gend Genome. (2018) 2:81-91. doi: 10.1177/2470289718801379

79. Giannopoulou E, Siatis KE, Metsiou D, Kritikou I, Papachristou DJ, Kalofonou $\mathrm{M}$, et al. The inhibition of aromatase alters the mechanical and rheological properties of non-small-cell lung cancer cell lines affecting cell migration. Biochim Biophys Acta. (2015) 1853:328-7. doi: 10.1016/j.bbamcr.2014.11.016

80. Hamilton DH, Griner LM, Keller JM, Hu X, Southall N, Marugan J, et al Targeting estrogen receptor signaling with fulvestrant enhances immune and chemotherapy-mediated cytotoxicity of human lung cancer. Clin Cancer Res. (2016) 22:6204-16. doi: 10.1158/1078-0432.CCR-15-3059

81. Lother SA, Harding GA, Musto G, Navaratnam S, Pitz MW. Antiestrogen use and survival of women with non-small cell lung cancer in Manitoba, Canada. Horm Cancer. (2013) 4:270-6. doi: 10.1007/s12672-013-0149-7

82. Perez EA, Gandara DR, Edelman MJ, O’Donnell R, Lauder IJ, DeGregorio M. Phase I trial of high-dose tamoxifen in combination with cisplatin in patients with lung cancer and other advanced malignancies. Cancer Invest. (2003) 21:1-6. doi: 10.1081/CNV-120016397

83. Wen S, Fu X, Li G, He L, Zhao C, Hu X, et al. Efficacy of tamoxifen in combination with docetaxel in patients with advanced non-small-cell lung cancer pretreated with platinum-based chemotherapy. Anticancer Drugs. (2016) 27:447-56. doi: 10.1097/CAD.0000000000000350

84. Stabile LP, Lyker JS, Gubish CT, Zhang W, Grandis JR, Siegfried JM. Combined targeting of the estrogen receptor and the epidermal growth factor receptor in non-small cell lung cancer shows enhanced antiproliferative effects. Cancer Res. (2005) 65:1459-70. doi: 10.1158/0008-5472.CAN-04-1872

85. Xu R, Shen H, Guo R, Sun J, Gao W, Shu Y. Combine therapy of gefitinib and fulvestrant enhances antitumor effects on NSCLC cell lines with acquired resistance to gefitinib. Biomed Pharmacother. (2012) 66:3849. doi: 10.1016/j.biopha.2012.02.004

86. Traynor AM, Schiller JH, Stabile LP, Kolesar JM, Eickhoff JC, Dacic S, et al. Pilot study of gefitinib and fulvestrant in the treatment of post-menopausal women with advanced non-small cell lung cancer. Lung Cancer. (2009) 64:51-9. doi: 10.1016/j.lungcan.2008.07.002

87. Garon EB, Pietras RJ, Finn RS, Kamranpour N, Pitts S, Marquez-Garban DC, et al. Antiestrogen fulvestrant enhances the antiproliferative effects of epidermal growth factor receptor inhibitors in human non-small-cell lung cancer. J Thorac Oncol. (2013) 8:270-8. doi: 10.1097/JTO.0b013e31827d525c

88. Garon EB, Siegfried JM, Stabile LP, Young PA, Marquez-Garban DC, Park DJ, et al. Randomized phase II study of fulvestrant and erlotinib compared with erlotinib alone in patients with advanced or metastatic non-small cell lung cancer. Lung Cancer. (2018) 123:91-8. doi: 10.1016/j.lungcan.2018. 06.013

Conflict of Interest: The authors declare that the research was conducted in the absence of any commercial or financial relationships that could be construed as a potential conflict of interest.

Copyright (c) 2021 Rodriguez-Lara and Avila-Costa. This is an open-access article distributed under the terms of the Creative Commons Attribution License (CC BY). The use, distribution or reproduction in other forums is permitted, provided the original author(s) and the copyright owner(s) are credited and that the original publication in this journal is cited, in accordance with accepted academic practice. No use, distribution or reproduction is permitted which does not comply with these terms. 